\title{
THE COUPLED BOUNDARY LAYERS AND AIR-SEA TRANSFER EXPERIMENT IN LOW WINDS
}

by James Edson, Timothy Crawford, Jerry Crescenti, Tom Farrar, Nelson Frew, Greg Gerbi, Costas Helmis, Tihomir Hristov, Djamal Khelif, Andrew Jessup, Haf Jonsson, Ming Li, Larry Mahrt, Wade McGillis, Albert Plueddemann, Lian Shen, Eric Skyllingstad, Tim Stanton, Peter Sullivan, Jielun Sun, John Trowbridge, Dean Vickers, Shouping Wang, Qing Wang, Robert Weller, John Wilkin, Albert J. Williams III, D. K. P. Yue, and Chris Zappa

Observations from a suite of platforms deployed in the coastal ocean are being combined with numerical models and simulations to investigate the processes that couple the atmosphere and ocean.

\footnotetext{
T
}

he need to better understand and model the interdependence of the ocean and atmosphere has long been recognized in the climate and weather communities. Work has been carried out to investigate how the upper ocean responds to the atmosphere, leading to $1 \mathrm{D}$ models of the upper-ocean response to the atmosphere (e.g., Kraus and Turner 1967; Price et al. 1986), and more recently to fully three-dimensional (3D) ocean boundary layer (OBL) models employing closure schemes similar to those used in the atmospheric boundary layer $(\mathrm{ABL}$; e.g., Mellor and Yamada 1982; Large et al. 1994). However, progress on fully two-way coupled models has been slower, particularly on shorter, weather-related time scales.

There are a number of reasons for this; for example, the dynamics of the coupled marine boundary layers are driven by a myriad of processes (Fig. 1) that impact the exchange of momentum, heat, and mass. However, the param-

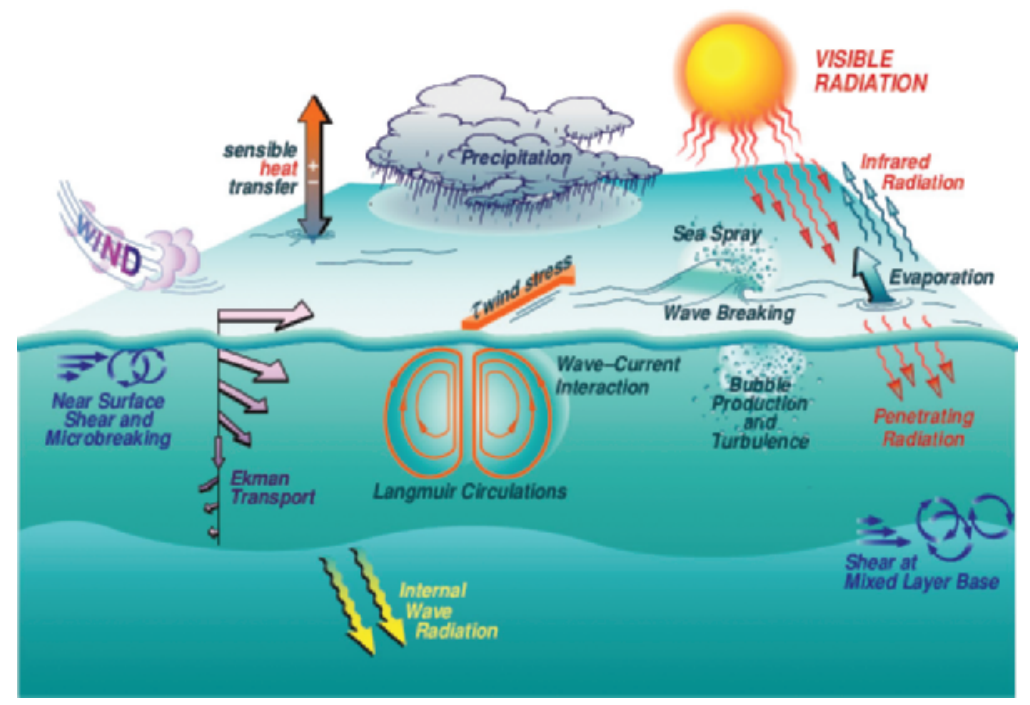

FIG. I. A few of the physical processes governing air-sea exchange across the coupled boundary layers. 
eterizations required to simulate these processes contain too much uncertainty, and oceanographic models of the ocean surface are not sufficiently advanced to provide the necessary surface boundary conditions. Additionally, observations of the marine environment lack the necessary temporal and spatial resolution required to initialize these models. As a result, there has been insufficient evidence that the inclusion of a dynamic ocean would improve 3-5-day atmospheric forecasts.

Now, however, there is increasing evidence that fully coupled models can often improve marine forecasts over shorter time scales. This is true in coastal regimes where air-land-sea contrasts drive mesoscale atmospheric circulations, fog formation, coastal upwelling, and tidal mixing. This is also true of hurricane forecasts, where accurate predictions of the heat, mass, and momentum exchange are crucial to accurately predict the intensity of the storm. All of these predictions rely on accurate estimates of the sea surface temperature at temporal and spatial resolution that are often not provided by satellite observations, particularly near the coastline and in severe weather. Progress now underway to improve coupled models stems from 1) significant improvements in ocean models over the past decade, and 2) observing initiatives that provide data needed to initialize these models and assess the success of different parameterizations. This article, and its companion articles in this issue, focuses on a recent program designed to improve coupled models in both low- and extreme wind conditions.

CBLAST. The Coupled Boundary Layers and AirSea Transfer (CBLAST) program was a major Office of Naval Research (ONR)-sponsored investigation that looked at two extremes of the marine environ- ment where coupled ocean-atmosphere processes had a clear impact on both boundary layers. At one extreme, investigators in the CBLAST-Hurricane component are attempting to improve hurricane intensity forecasts and our understanding of the ocean's response as described in the companion articles by Black et al. (2007) and Chen et al. (2007).

CBLAST-LOW was designed to investigate coupled boundary layer (CBL) processes at the lowwind extreme where the processes are often driven or strongly modulated by buoyant forcing. The focus was on conditions ranging from negligible wind stress, where buoyant forcing dominates, up to wind speeds where wave breaking and Langmuir circulations play a significant role in the exchange processes. Additionally, as CBLAST-LOW developed, it became apparent that other wave-driven processes could not be ignored, including the impact of ocean swell from distant storms on the coupled boundary layer structure.

The goal of CBLAST-LOW is therefore to improve our understanding of the processes that couple the marine boundary layers under these conditions using observations, numerical simulations, and models. The ultimate goal is to incorporate a new and/or improved parameterization of these processes in coupled models to improve marine forecasts of wind, waves, and currents. The article begins by briefly describing the region where CBLAST-LOW was conducted. It then describes the observational and modeling components and provides examples of how these components are being combined to meet the CBLAST objectives.

\section{SITE DESCRIPTION. CBLAST-LOW was} conducted during intensive operating periods (IOPs) in the summers of 2001 through 2003 in
AFFILIATIONS: Edson-University of Connecticut, Avery Point, Groton, Connecticut; CRAWFORD*_NOAA/ARL, Idaho Falls, Idaho; Crescenti-FPL Energy, Juno Beach, Florida; Farrar, Frew, Gerbi, Plueddemann, Trowbridge, Weller, and Williams-Woods Hole Oceanographic Institution, Woods Hole, Massachusetts; HeLmISUniversity of Athens, Athens, Greece; HRISTOV AND SHEN-Johns Hopkins University, Baltimore, Maryland; KHELIF-University of California, Irvine, California; Jessup—Applied Physics Laboratory, University of Washington, Seattle, Washington; JoNsSON-CIRPAS, Monterey, California; LI-Center for Environmental Sciences, University of Maryland, Cambridge, Maryland; MAHRT, SKYLLINGSTAD, AND VICKERS—Oregon State University, Corvallis, Oregon; McGILLIS AND ZAPPA-Lamont Doherty Earth Observatory, Columbia University, Palisades, New York; STANTON AND Q. WANG-Naval Postgraduate School, Monterey, California; SUluIvan AND SUN-
National Center for Atmospheric Research, Boulder, Colorado; S. WANG—Naval Research Laboratory, Monterey, California; WILKIN-Rutgers University, New Brunswick, New Jersey; YUEMassachusetts Institute of Technology, Cambridge, Massachusetts *Deceased CORRESPONDING AUTHOR: James Edson, University of Connecticut, Avery Point, Department of Marine Sciences, 1080 Shennecosset Road, Groton, CT 06340

E-mail: james.edson@uconn.edu

The abstract for this article can be found in this issue, following the table of contents.

DOI:I0.|I75/BAMS-88-3-34|

In final form 18 September 2006

(C)2007 American Meteorological Society 
the Atlantic Ocean south of Martha's Vineyard (Fig. 2). The CBLAST-LOW region is bounded to the north by Martha's Vineyard, and Nantucket, Massachusetts, with shoals in between. Noman's Island to the west and Wasque Shoals to the east limit the fetch, and thereby wave development, for wind from those directions near the coastline of Martha's Vineyard. However, the fetch is essentially infinite for southerly wind directions.

Continuous observations of the ocean and atmosphere are maintained at the Martha's Vineyard Coastal Observatory (MVCO), which includes a meteorological mast on the beach and a bottommounted sea node (Fig. 3). These platforms support sensors that have operated continuously (with the exception of maintenance activities) since 2001. Therefore, the time series from the MVCO provides the beginning of a local climatology from $5 \mathrm{y}$ of continuous operation, which can be compared with individual years. For example, Figs. $4 \mathrm{a}$ and $5 \mathrm{a}$ provide histograms of the wind speeds and wind directions, respectively, measured at the meteorological mast during July and August. The accumulated data indicate that the predominant winds are from the southwest, with wind speeds typically reaching 2-6 $\mathrm{m} \mathrm{s}^{-1}$. As such, the wind directions are predominantly from the open ocean. The main IOP in the summer of 2003 was fairly typical (Figs. $4 \mathrm{~b}$ and $5 b$ ), with wind speeds and directions that were slightly lighter and more southerly, respectively, than the composite.

Oceanic variables are also continuously available from the MVCO sea node. The currents in the CBLAST region are dominated by tides and fluctuate between 0 and
$0.5 \mathrm{~m} \mathrm{~s}^{-1}$. The sea surface elevation changes by approximately $\pm 0.5 \mathrm{~m}$ during a tidal cycle. The tidally averaged mean surface currents are $\mathrm{O}\left(10 \mathrm{~cm} \mathrm{~s}^{-1}\right)$ and flow from east to west near the coast of Martha's Vineyard. The sea temperature measured at a depth of $11 \mathrm{~m}$ averaged $19.0^{\circ} \mathrm{C}$ during the 5 -yr period and $18.9^{\circ} \mathrm{C}$ during the $2003 \mathrm{IOP}$.

\section{CBLAST 2003 Offshore Array}

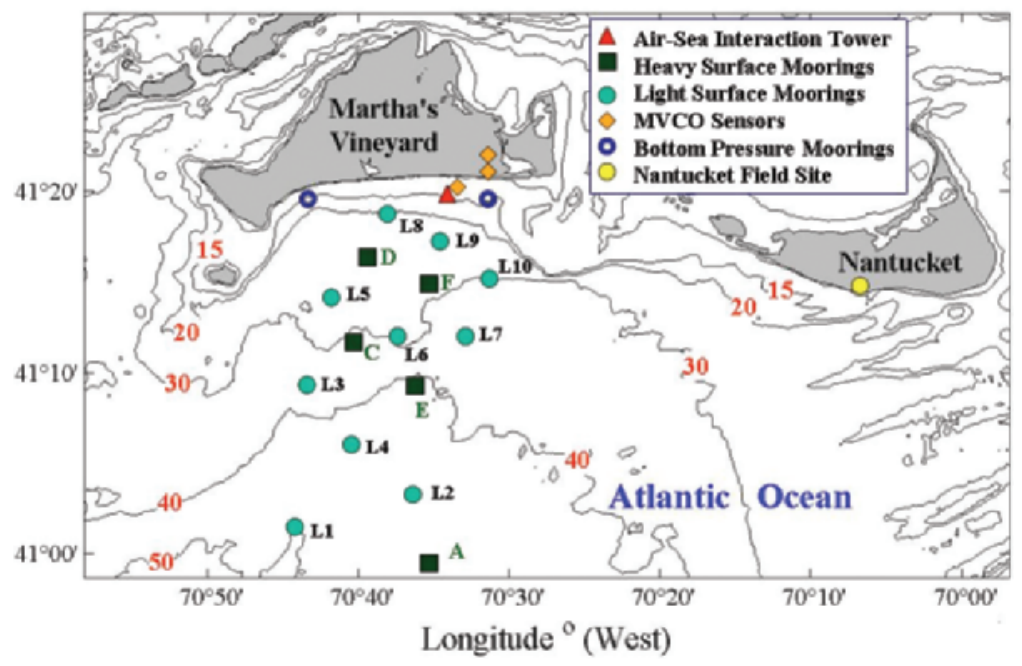

FIG. 2. A diagram of the CBLAST region showing the location of the Nantucket field site, surface moorings, ASIT, subsurface moorings, and MVCO sensors deployed during the IOP in the summer 2003. The lines indicate the bathymetry and the isobaths are given in meters using red numbers.

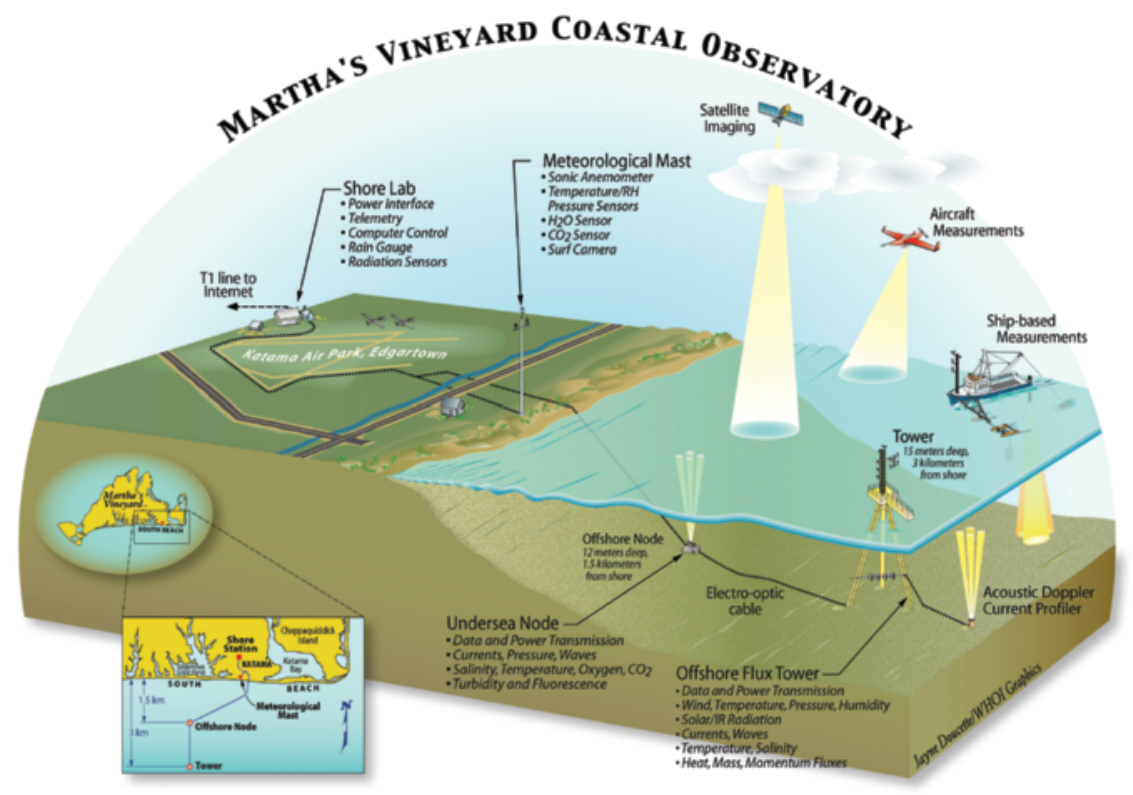

Fig. 3. A schematic representation of the MVCO showing the location of the meteorological mast, sea node, and ASIT. The cutout shows the actual location of these elements on the south shore of Martha's Vineyard. 

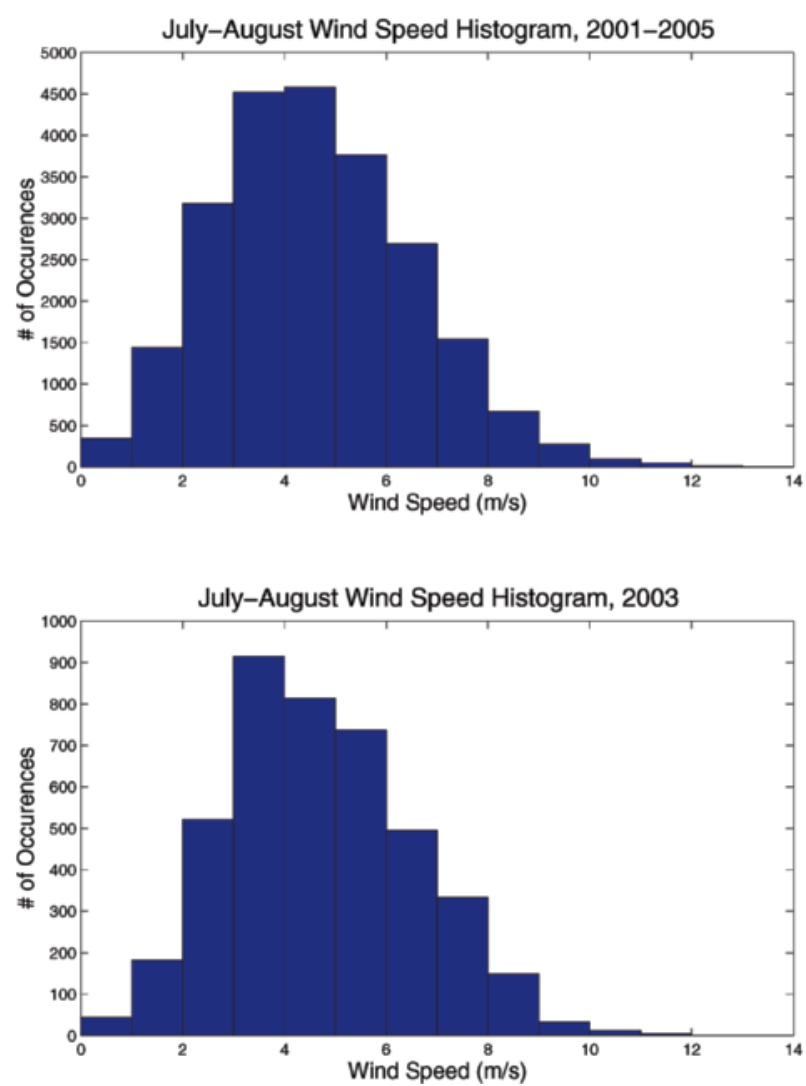

Fig. 4. Histograms of wind speed data collected at the MVCO during the months of July and August; (top) the composite of all data taken from $200 \mathrm{I}$ to 2005, and (bottom) data from 2003.

OBSERVATIONAL COMPONENTS. CBLASTLOW deployed an extensive array of observational components during the IOPs. A wide range of temporal and spatial scales was sampled using an array of fixed and mobile platforms, including an offshore tower, surface moorings, aircraft, ships, rawinsondes, satellites, and the MVCO. The periods of operation for the various platforms during the 2001-03 IOPs are provided as timelines at the CBLAST-LOW Web site (online at www.whoi.edu/science/AOPE/dept/ CBLAST/low/timelines.html). Data collected from these platforms are also available from the CBLASTLOW Web site (www.whoi.edu/science/AOPE/dept/ CBLAST/low/data.html).

Air-Sea Interaction Tower. Marine researchers have long sought stable ocean platforms that would allow studies of turbulent air-sea exchanges. A primary technological objective of the CBLAST-LOW program was to build an Air-Sea Interaction Tower (ASIT) to enable long-duration studies of the processes on both sides of the air-sea interface. ASIT is a low-profile fixed structure that minimizes flow distortion and
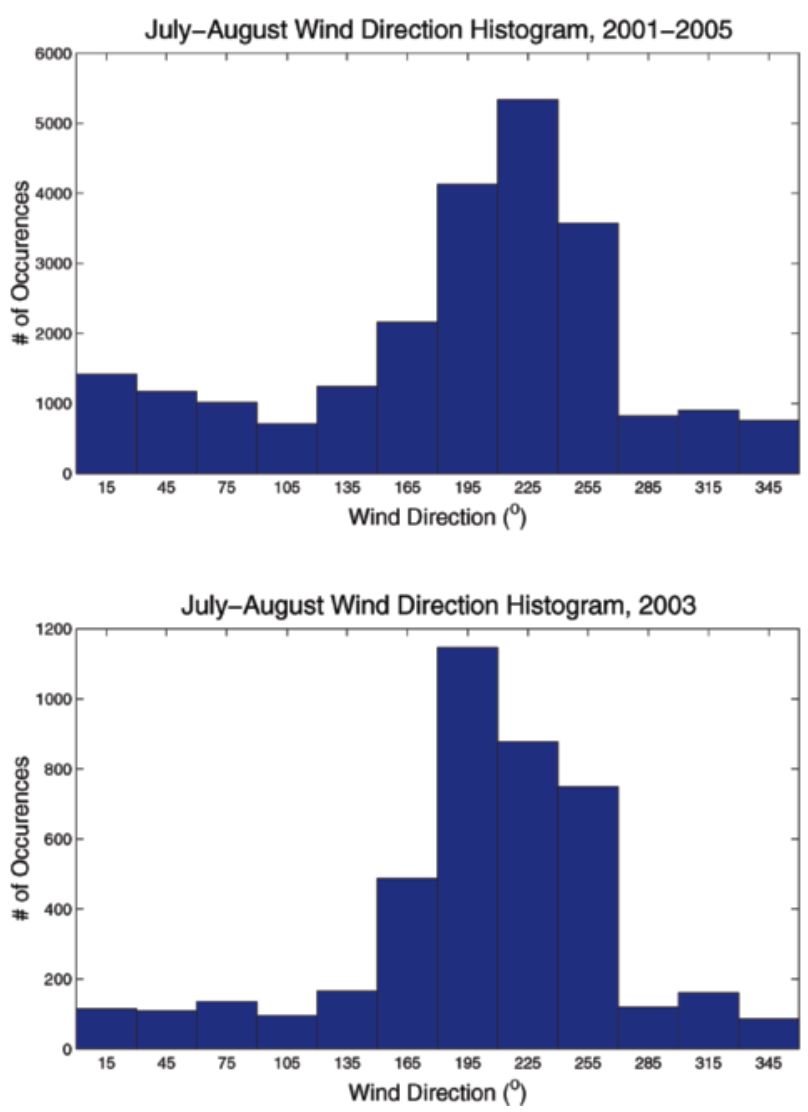

FIG. 5. Histograms of wind direction data collected at the MVCO during the months of July and August; (top) composite of all data taken from $200 \mathrm{I}$ to 2005, and (bottom) data from 2003.

removes the need for motion correction. It is located $3.2 \mathrm{~km}$ south of Martha's Vineyard in 15-m-deep water (Figs. 2 and 3), and was completed in the summer of 2002. It is attached by cable to the MVCO, which provides power $(4 \mathrm{~kW})$ and a high-bandwidth (1 GB) data link (Austin et al. 2002).

Atmospheric sensors at fixed heights and on a vertical profiler were deployed on the ASIT during the 2003 IOP to directly measure the vertical exchange of momentum, heat, and moisture that couples the boundary layers. The air-side components included sensors to measure the mean and turbulent wind velocity, air temperature, specific humidity, and pressure, as well as precipitation, solar and infrared radiation, sea surface temperature, and wave height (Fig. 6a). The ASIT is exposed to infinite fetch for wind directions from $140^{\circ}$ to $250^{\circ}$ and is fetch limited from other directions, as described above.

Oceanographic sensors were deployed beneath the surface to make similar measurements of currents, temperature, and salinity. Turbulence sensors were mounted on horizontal booms spanning two legs of the ASIT (Fig. 6b) to provide direct estimates of 
momentum and heat exchange just below the surface. To our knowledge, this represents the first successful attempt to directly and simultaneously measure the heat and momentum exchange on both sides of the air-sea interface. The nominal sampling frequency of the all-turbulence and -wave instrumentation was $20 \mathrm{~Hz}$. The type and location of the fixed sensors on and nearby ASIT are summarized in Table 1.

Surface mooring array. Surface mooring arrays were deployed in the CBLAST-LOW operating area south of Martha's Vineyard during all three field campaigns. Two moorings were deployed 20 and $40 \mathrm{~km}$ offshore in 2001 to collect records of surface forcing and temporal evolution of vertical ocean structure (Pritchard and Weller 2005). These records revealed the significant impact of synoptic weather systems on regional oceanographic variability. To resolve this variability and examine the ability of regional atmospheric and ocean models to simulate it, an array of six moorings was deployed from late June to early September 2002, spanning a $20 \mathrm{~km}$ wide $\times 40 \mathrm{~km}$ long region south of Martha's Vineyard (Wilkin 2007).

During the August 2003 IOP, surface meteorological and upper-ocean measurements were collected from 15 instrumented surface moorings (Fig. 2). Five "heavy" moorings supported surface meteorological sensors and in the ocean temperature, salinity, and velocity sensors had 2 -m vertical resolution. Ten "light" moorings supported temperature sensors with 2 -m vertical resolution. The goal was to obtain a continuous 3D picture of the oceanic temperature field to investigate mesoscale variability in upper-ocean dynamics and air-sea coupling.

Ship-based surveys. Ship-based operations where conducted during all three summers. During the August 2003 IOP, surface meteorological and upper-ocean measurements were collected by Fishing Vessel (F/V) Nobska during four survey cruises. The Nobska deployed and tracked five drifting buoys, each outfitted with a high-resolution $(0.5 \mathrm{~m})$ vertical temperature array and two levels of salinity measurements.

The Nobska also towed a similar vertical array with fast-response temperature or temperature/salinity sensors through targeted surface features and routinely made conductivity-temperature-depth (CTD) profiles. The ship carried upward- and downward-looking IR radiometers to estimate the sea surface temperature (SST), a direct covariance flux system (DCFS), and shortwave and longwave radiometers to make continuous measurements of the momentum, heat, mass, and radiative fluxes during the oceanic surveys (Fig. 7a).

Surfactant film distributions were surveyed during the 2002 and 2003 IOPs using a new survey tool, the Slick Chemical Identification and Measurement System (SCIMS). SCIMS is a semiautonomous mobile instrument platform deployed off the Research Vessel $(\mathrm{R} / \mathrm{V})$ Asterias that detects the presence of surface microlayer films and allows mapping of their spatial and temporal distributions (Fig. 7b). Measurements to characterize surface films were carried out under different wind stress conditions in order to determine the patchiness of surface film distributions on scales ranging from $10 \mathrm{~m}$ to $5 \mathrm{~km}$.

Aircraft measurements. Three aircraft participated in CBLAST-LOW: A Cessna Skymaster provided IR remote sensing, and two aircraft provided measurements of the mean and turbulent structure of the ABL. The National Oceanic and Atmospheric
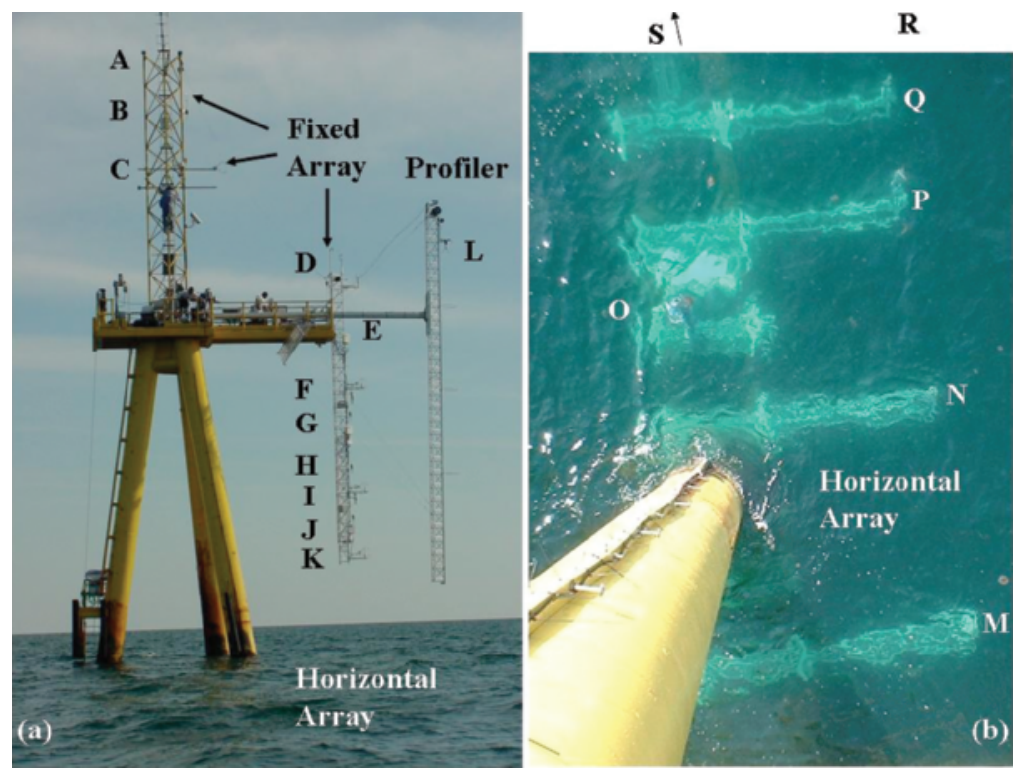

FIg. 6. (a) Experimental setup for the ASIT during CBLAST. The photo indicates the location of the fixed array, profiler, and subsurface horizontal array. (b) The subsurface horizontal array photographed from ASIT. The booms extending out from the crossbeam booms support fast-response velocity and temperature sensors. The letters are used to reference the location of the instruments that are summarized in Table I. 
TABLE I. Instrumentation deployed on and around ASIT during the 2003 IOP.

\begin{tabular}{|c|c|c|c|}
\hline Sensors & Variables & Location on Fig. 6 & $\begin{array}{c}\text { Nominal measurement } \\
\text { height(s) }\end{array}$ \\
\hline Pyrgeometer & IR radiative flux & A & $22 \mathrm{~m}$ \\
\hline Pyranometer & Solar radiative flux & $A$ & $22 \mathrm{~m}$ \\
\hline Sonic anemometer & $\begin{array}{c}\text { Fast-response three-component } \\
\text { velocity, temperature }\end{array}$ & B, C, D & $20,18,15 \mathrm{~m}$ \\
\hline Rain gauge & Precipitation & $\mathrm{D}$ & $13 \mathrm{~m}$ \\
\hline Pressure sensor & Mean pressure. & C, F, G, I & $18,10,9,6.5 \mathrm{~m}$ \\
\hline $\begin{array}{l}\text { Temperature/relative humidity } \\
\text { sensor }\end{array}$ & $\begin{array}{c}\text { Mean temperature, relative } \\
\text { humidity }\end{array}$ & $B, C, D, G, H, J$ & $21,18,13.5,9,7,5 \mathrm{~m}$ \\
\hline $\begin{array}{c}\text { Sonic anemometer, infrared } \\
\text { hygrometer }\end{array}$ & $\begin{array}{l}\text { Fast-response three-component } \\
\text { velocity, temperature, water vapor }\end{array}$ & $\mathrm{F}, \mathrm{I}, \mathrm{K}$ & $10,6.5,4 \mathrm{~m}$ \\
\hline Static pressure sensor & Fast-response static pressure & $\mathrm{F}, \mathrm{I}$ & $10,6.5 \mathrm{~m}$ \\
\hline $\begin{array}{l}\text { Profiling package; } T-\mathrm{RH} \text { sensor, } \\
\text { sonic anemometer }\end{array}$ & $\begin{array}{l}\text { Mean temperature, relative } \\
\text { humidity, horizontal velocity }\end{array}$ & L & $2.5-16 \mathrm{~m}$ \\
\hline Radiometer & Sea surface temperature & $\mathrm{E}$ & $0 \mathrm{~m}$ \\
\hline $\begin{array}{l}\text { Laser altimeter, microwave } \\
\text { altimeter }\end{array}$ & Surface elevation, wave height & $E$ & $0 \mathrm{~m}$ \\
\hline Microwave altimeter & Surface elevation, wave height & $E$ & $0 \mathrm{~m}$ \\
\hline Fanbeam ADCP & 2D maps of surface velocities & Seafloor & $0 \mathrm{~m}$ \\
\hline $\begin{array}{l}\text { High-resolution acoustic } \\
\text { Doppler current profiler } \\
\text { (ADCP) }\end{array}$ & Current profiles & $\mathrm{S}$ (end of beam) & -3.5 to $0 \mathrm{~m}$ \\
\hline $\begin{array}{l}\text { Acoustic Doppler velocimeter } \\
\text { (ADV), thermistor }\end{array}$ & $\begin{array}{c}\text { Fast-response three-component } \\
\text { velocity and temperature }\end{array}$ & $N, P$ & $-3.5 \mathrm{~m}$ \\
\hline ADV & Fast-response 3-component velocity & $M, Q, R$ & $-3.5 \mathrm{~m}$ \\
\hline ADV, pressure & $\begin{array}{l}\text { Fast-response three-component } \\
\text { velocity, wave height, and direction }\end{array}$ & $\mathrm{S}$ (end of beam) & $-3.5 \mathrm{~m}$ \\
\hline CTD sensor & Salinity, temperature, depth & $O$ and seafloor & $-1.5,-5,-12 m$ \\
\hline $\begin{array}{l}\text { Broadband acoustic Doppler } \\
\text { current profiler (BADCP) }\end{array}$ & $\begin{array}{l}\text { Current profiles, vertical velocity } \\
\text { profile }\end{array}$ & Seafloor & -13 to $-0.5 \mathrm{~m}$ \\
\hline $\mathrm{ADCP}$ & Current profiles & Seafloor & -13 to $-0.5 \mathrm{~m}$ \\
\hline Current meter & $\begin{array}{l}\text { Fast response three-component } \\
\text { velocity }\end{array}$ & Seafloor & $-12 m$ \\
\hline
\end{tabular}

Administration's (NOAA's) Long-EZ airplane (N3R) provided measurements of atmospheric turbulence from $10 \mathrm{~m}$ to the top of the boundary layer. The aircraft is instrumented with a suite of sensors to measure wind velocity, pressure, air temperature, humidity, and net (long- and shortwave) radiation. Direct covariance fluxes of heat, moisture, and momentum are derived using the approach described by Vickers et al. (2001). Results from the 2001 IOP are reported by Vickers and Mahrt (2006).

The Center for Interdisciplinary Remotely Piloted Aircraft Studies (CIRPAS) Pelican is a similarly instrumented aircraft designed to measure atmo- spheric turbulence, mean variables, and remotely sensed sea surface characteristics. The Pelican was used to map atmospheric boundary layer structure in support of the CBLAST-LOW 2003 investigations.

IR remote sensing. Measurements of SST variability were made in 2001 from the Long-EZ and in 2002 and 2003 from the Cessna Skymaster. The Skymaster supported a state-of-the-art, high-spatial-resolution IR imaging system providing calibrated, sky-corrected imagery of SST (Zappa and Jessup 2005). A downwardlooking digital videocamera was used to characterize the sea surface conditions. The surveys in 2002 and 
2003, coordinated with the ship surveys, quantified the horizontal mesoscale variability in the SST field (Fig. 8) and investigated links between SST variability, ABL structure, and air-sea fluxes.

Nantucket field site. The Nantucket Island site, about $45 \mathrm{~km}$ east-southeast of the ASIT (Fig. 2), supported rawinsonde launches (Loran-C sondes) every 46 hours, continuous sampling of the lower boundary layer from a sodar, a ceilometer to measure cloud-base height, and turbulence and mean measurements from a flux tower. The measurement periods were between 31 July and 23 August in 2002 and from 22 July to 27 August in 2003.

COUPLED MODELS. One of the main objectives of the CBLAST-LOW project is to improve surface and boundary layer parameterizations in Naval Research Laboratory's Coupled Ocean-Atmosphere Mesoscale Prediction System (COAMPS) for low-wind conditions. Real-time COAMPS weather forecasts provided for the CBLAST-LOW field experiment are being used with the measurements to evaluate the model physics and investigate the impacts of air-sea interaction on the mesoscale weather prediction.

The COAMPS model (Hodur 1997) has surface fluxes computed using a

Fig. 8. (left) An Illustrative example of the SST maps provided by the IR system overlaid on the bathymetry. These preliminary images were provided to a CBLASTLOW PI after each run to assist in coordinated ship and aircraft observations. (right) An example of the high-resolution IR imagery deployed from the Cessna aircraft. The color region represents a 444-m-wide swath of SST anomaly relative to a $2.3-\mathrm{km}$ along-track smoothed SST field. modified Louis scheme (Louis 1979) as described by Wang et al. (2002). The domain configuration for the real-time atmospheric forecast includes three horizontally nested grids of 27,9 , and $3 \mathrm{~km}$, and 30 vertical levels. The SST used in forecasts was assimilated using satellite retrievals and ship observations.

An example of COAMPS-derived humidity and temperature fields compared against the rawinsonde
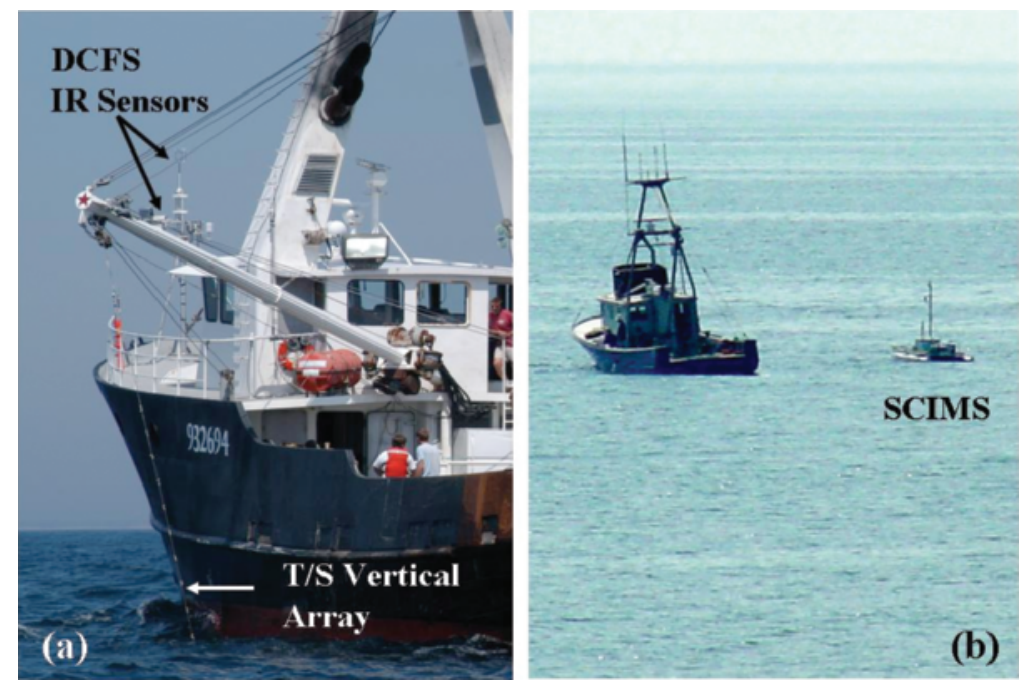

FIG. 7. (a) Instrumentation deployed on the Nobska during the 2003 IOP. Bow instrumentation included a direct covariance flux system and IR radiometers. The boom supported an array of temperaturesalinity sensors for high-resolution vertical profiles. (b) Photo taken from the Air-Sea Interaction Tower at MVCO of the SCIMS catamaran accompanied by R/V Asterias during a southeasterly survey transect on 15 Aug 2003. Numerous banded surface film features (light areas) evident in the field of view were quantified by SCIMS instrumentation.

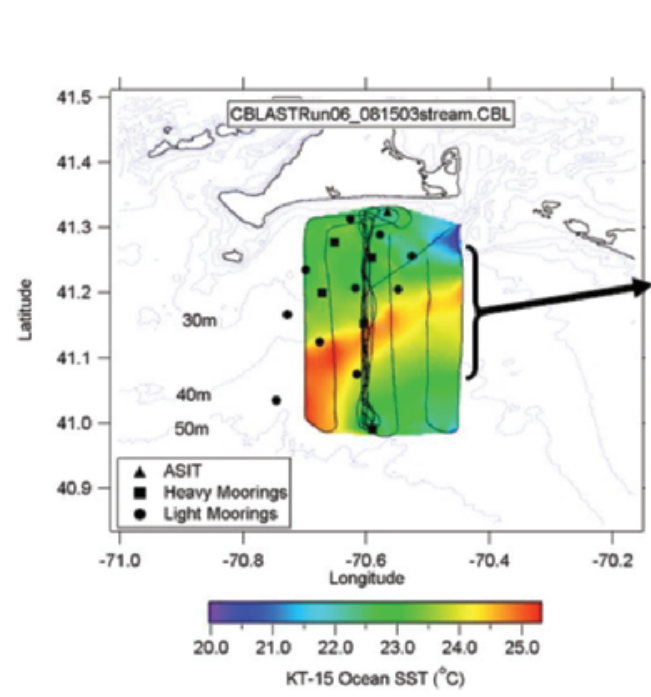

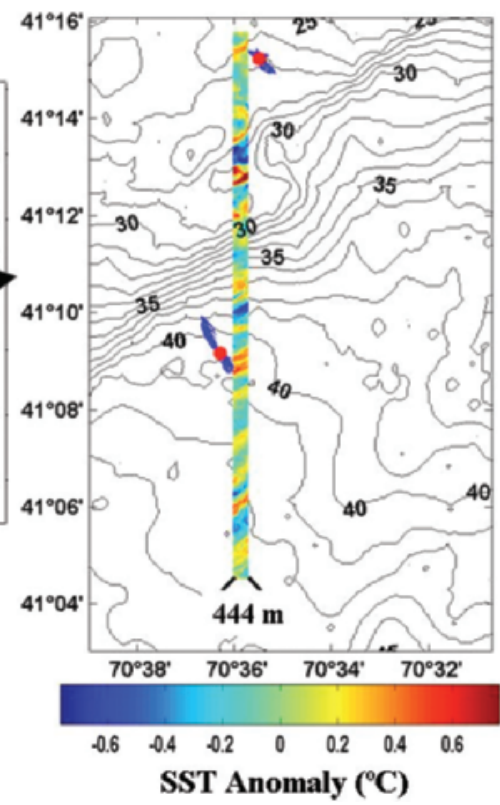



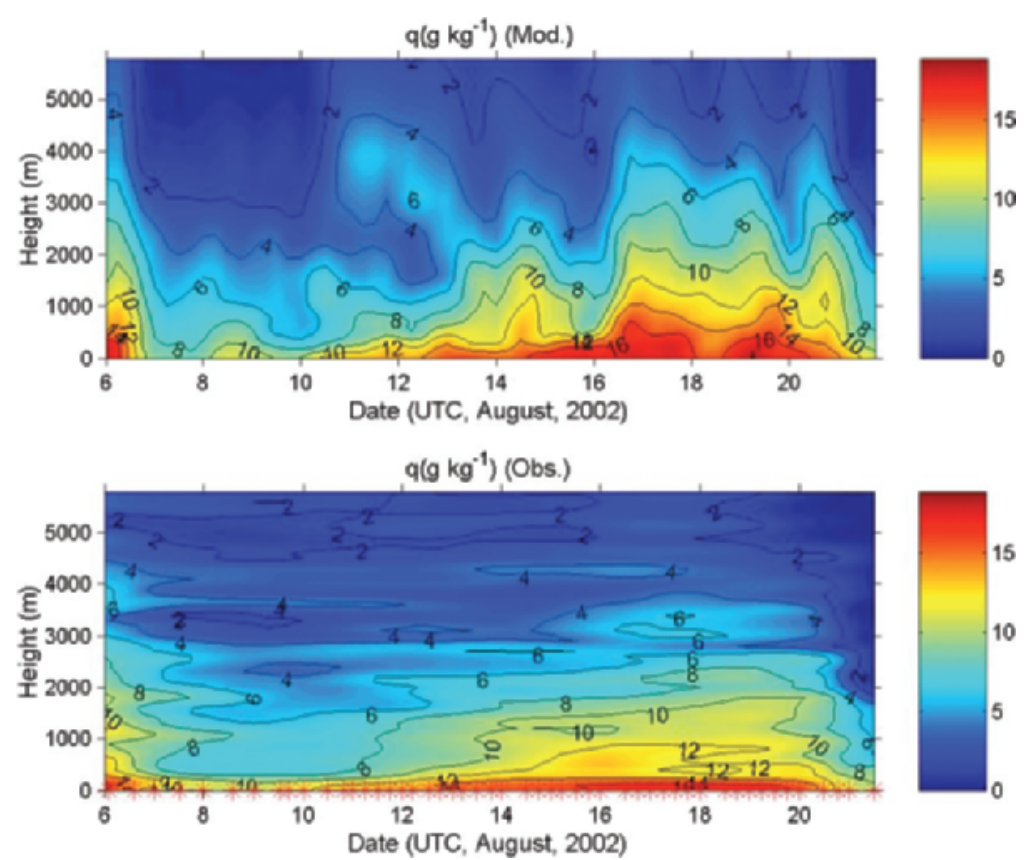

Fig. 9. Temporal evolution of specific humidity vertical profiles from (top) COAMPS 3-km grid results, and (bottom) the Nantucket rawinsonde launches. The red (*) at the bottom indicates the time of all soundings used to generate the plot.
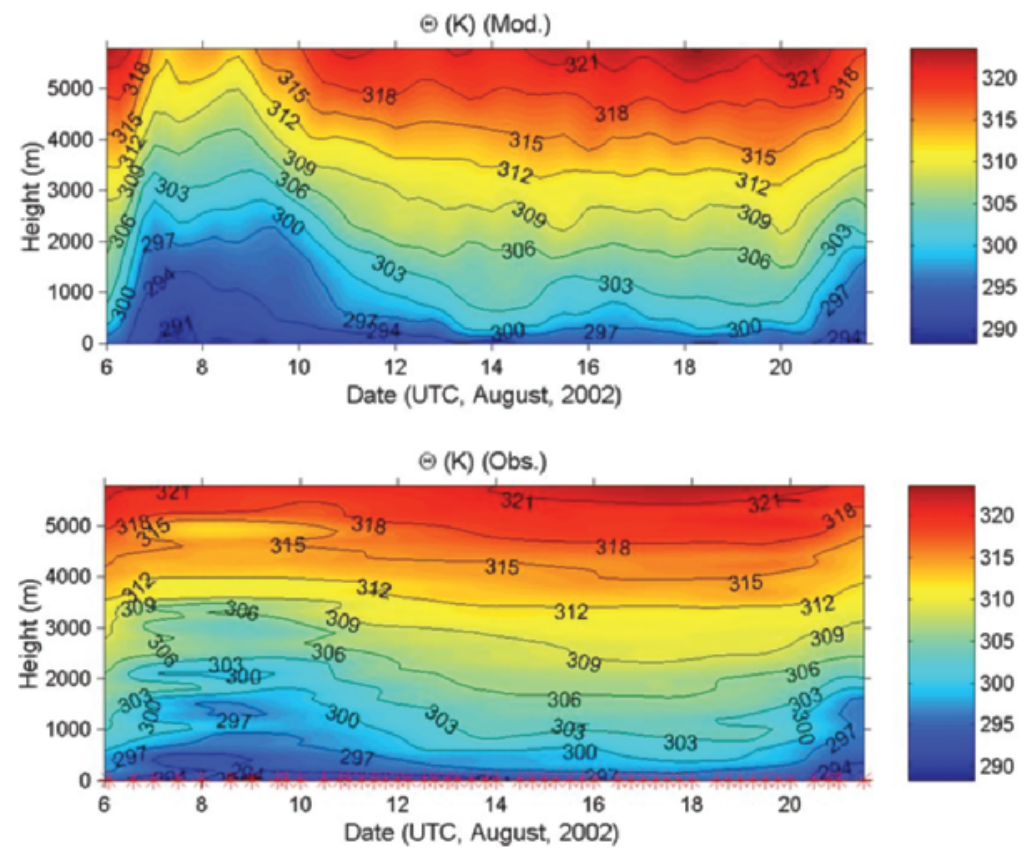

Fig. 10. Same as Fig. 9 except for temporal evolution of potential temperature.

data for August 2002 is shown in Figs. 9 and 10. The general trend of the forecast agrees well with observations. This includes the drying and cooling trend observed during the first 10 days when low pressure systems over the continental United
States frequently interrupted the high pressure pattern off of the east coast. The southwesterly winds again dominated after 14 August 2002 , providing warm and moist air to the CBLAST area. It is evident that COAMPS produced a moister boundary layer (below $1 \mathrm{~km}$ ) between 16 and 20 August and a cooler boundary layer between 6 and 10 August. The predicted cooler marine boundary layer may be partly attributed to the known near-surface cold bias over land in COAMPS, which was advected to the CBLAST-LOW area.

Another objective of CBLAST was to couple the mesoscale atmospheric model in COAMPS with the Regional Ocean Modeling System (ROMS). ROMS is a highresolution hydrodynamic model that has gained wide acceptance in the oceanographic community. ROMS was formulated for the region using detailed bathymetry. The model is forced by tides, outer-shelf climatological inflows, observed downward radiative fluxes, and air-sea heat and momentum fluxes derived from the model SST and COAMPS forecast atmospheric conditions (Wilkin and Lanerolle 2005).

The three-dimensional evolution of regional ocean thermal stratification was simulated successfully, as validated by comparisons to mooring observations (Fig. 11) and satellite imagery (Wilkin 2007). Tides proved important to the regional circulation, and accurate representation of tidal variability in the model was achieved by assimilation of sea level data to adjust the tidal harmonic forcing open boundary conditions (He and Wilkin 2006). One role for ROMS is to provide insight into processes not resolved observationally. For example, lateral advection and submesoscale mixing of heat are potentially significant in the local heat budget, and ROMS was used to gauge the magnitude of horizontal heat transport compared to air-sea heat transfer (Wilkin 2007). 


\section{COUPLED BOUNDARY LAYER PROCESSES. Marine} scientists have long relied on flux-profile relationships that relate the turbulence fluxes of momentum, heat, and moisture to their respective profiles of velocity, temperature, and water vapor. These relationships have been investigated in overland experiments since the mid-1960s, and a number of similar semiempirical functions such as the commonly used Businger-Dyer formulas (Businger 1988) have been proposed. This approach is reasonably accurate as long as the boundary layer is horizontally homogeneous and the turbulent exchange is driven by a combination of mechanical and buoyant forcing. However, the coastal boundary layers are often characterized by significant mesoscale variability in, for example, surface temperature and roughness. Additionally, near the ocean surface, wave-induced forcing is expected to influence the characteristics of the near-surface flow.

Wave-induced effects have been shown to cause a substantial departure from land-based parameterizations (e.g., Vickers and Mahrt 1999; Smedman et al. 1999; and Hare et al. 1997) in the wave boundary layers (WBLs). The WBLs are defined in this overview as the region where the total momentum flux, even if assumed to be constant with height, has a significant wave-induced component (e.g., Hristov et al. 2003). Because land-based parameterizations are formulated for turbulently driven processes, they become increasingly inaccurate in the WBL as one nears the surface. This applied to both the atmospheric and ocean boundary layers. For example, coherent structures in the mixed layer, known as Langmuir circulations, are driven by wave-current interactions. These structures are believed to transport buoyancy and momentum and enhance mixing. Additionally, intermittent turbulence and additional mixing is generated by wave breaking. Neither of these processes is generally included in flux-profile relations, which implies that these processes are not accounted for in most models.

CBLAST-LOW data analysis and modeling efforts are directed toward improved understanding of how mesoscale variability and wave-related processes affect the coupled boundary layer. Many of the investigations in CBLAST-LOW have relied on large-eddy simulations (LES) and direct numerical simulations (DNS) to guide the observational process studies as summarized in Table 2 . The numerical results provide a context for interpreting our measurements and investigating resolved processes, while our measurements have provided a means to evaluate subgrid-scale parameterizations required by the models. For example, in the process studies described below, LES is used to guide investigations of wind-swell interaction, and the impact of SST variability on the coupled boundary layers.

In the sections that follow, we present selected results in two areas: air-sea momentum transfer and the influence of sea surface properties and ABL structure. A more complete description of CBLASTLOW analysis and modeling results are available online at www.whoi.edu/science/AOPE/dept/CBLAST/ low/cblastlow.html.

Air-sea momentum exchange. The bulk aerodynamic formulas parameterize the sensible heat, latent heat, and momentum fluxes in terms of the more easily measured mean or bulk quantities using transfer coefficients. The transfer coefficient for momentum, that is, the drag coefficient, computed from the CBLAST-LOW dataset, shows good agreement in the mean with the COARE 3.0 algorithm (Fairall et al. 2003), particularly between 4 and $12 \mathrm{~m} \mathrm{~s}^{-1}$, as shown in Fig. 12. However, there is significant disagreement between the bin-averaged data and the parameterization at the lowest and highest wind speeds.

We hypothesize that the larger values of the drag coefficient at high winds speeds is likely due to shoaling waves that produce steeper waves and enhanced breaking. Preliminary indications are that 
TABLE 2. Simulations studies conducted in support of CBLAST.

\begin{tabular}{|c|c|c|}
\hline Study & Simulation & PI(s) \\
\hline $\begin{array}{c}\text { Turbulence airflow over swell and its impact } \\
\text { on wave boundary layer structure }\end{array}$ & $\begin{array}{c}\text { Atmospheric LES with BC conditions imposed } \\
\text { by resolved waves (swell) and parameterized } \\
\text { surface roughness }\end{array}$ & $\begin{array}{l}\text { P. Sullivan, J. Edson, } \\
\text { J. McWilliams, T. Hristov }\end{array}$ \\
\hline $\begin{array}{l}\text { Simulations of atmospheric boundary layer in } \\
\text { CBLAST region }\end{array}$ & $\begin{array}{l}\text { Atmospheric LES using boundary conditions } \\
\text { from COAMPS mesoscale model }\end{array}$ & P. Sullivan, S. Wang \\
\hline $\begin{array}{l}\text { Simulation of atmospheric boundary layer } \\
\text { evolution over mesoscale SST fronts }\end{array}$ & $\begin{array}{c}\text { Atmospheric LES over step changes in sea } \\
\text { surface temperature }\end{array}$ & $\begin{array}{c}\text { E. Skyllingstad, L. Mahrt, } \\
\text { D. Vickers }\end{array}$ \\
\hline $\begin{array}{l}\text { Detailed studies of the coupling mechanism } \\
\text { between the air and water turbulent flows }\end{array}$ & $\begin{array}{l}\text { DNS using fully nonlinear free-surface coupled } \\
\text { boundary conditions }\end{array}$ & D. K. P. Yue, L. Shen \\
\hline $\begin{array}{l}\text { Simulations of the effect of wave breaking on } \\
\text { the ocean surface layer }\end{array}$ & Oceanic DNS with stochastic wave breaking & $\begin{array}{l}\text { P. Sullivan, J. McWilliams, } \\
\text { K. Melville }\end{array}$ \\
\hline $\begin{array}{l}\text { Impacts of breaking waves and Langmuir } \\
\text { circulation on the ocean mixed layer }\end{array}$ & $\begin{array}{l}\text { Ocean LES with Craik-Leibovich vortex force } \\
\text { and intermittent stress transmission from a } \\
\text { spectrum of breaking wave events }\end{array}$ & $\begin{array}{l}\text { P. Sullivan, J. McWilliams, } \\
\text { K. Melville }\end{array}$ \\
\hline $\begin{array}{l}\text { Deepening of the ocean mixed layer by } \\
\text { Langmuir and shear turbulence }\end{array}$ & $\begin{array}{l}\text { Stratified ocean LES with Craik-Leibovich } \\
\text { vortex force and constant surface stress }\end{array}$ & M. Li, A. Plueddemann \\
\hline
\end{tabular}

a number of physical processes driven by wind-wave interaction are responsible for the disagreement at low wind speeds. For example, for conditions with weak winds following a faster-moving swell, the wind stress may be reduced relative to the bulk prediction. These conditions are known as old seas and are commonly
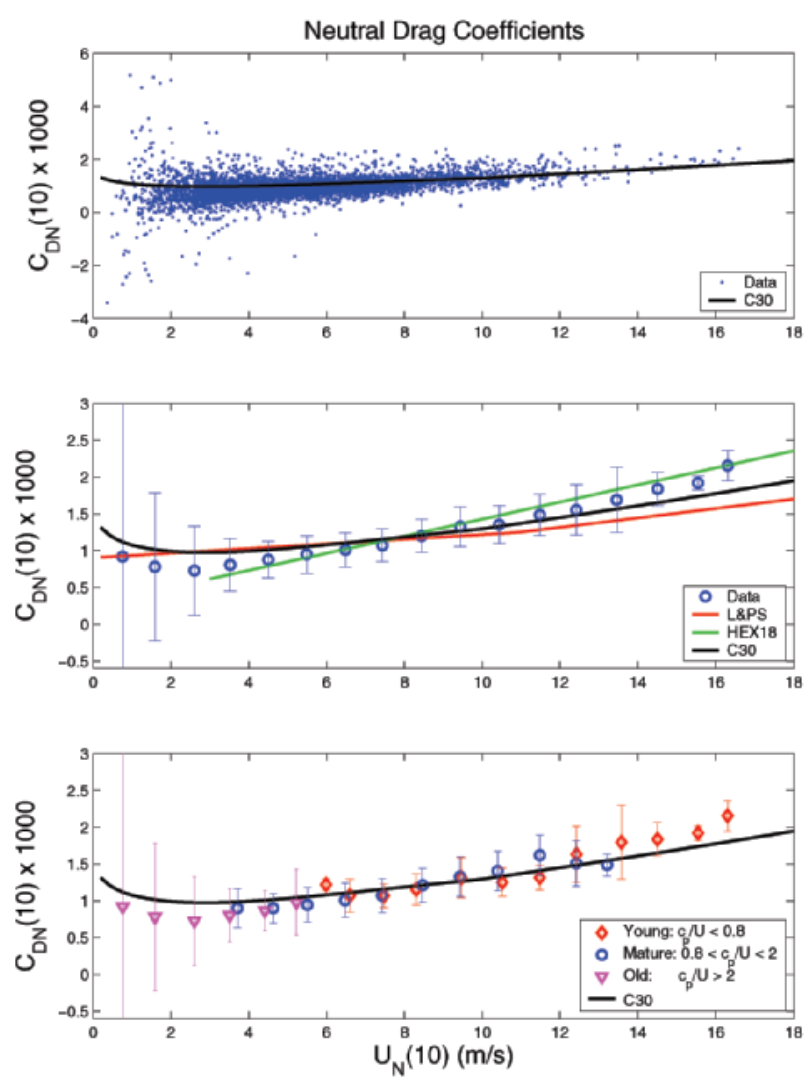

found over the ocean whenever nonlocally generated waves propagate into a low-wind region or whenever local seas slowly decay as a storm moves out of the region.

The sea state can be characterized by the wave age parameter $c_{p} / U$, where $c_{p}$ is the phase speed of the dominant waves and $U$ is the wind speed. The wave age of a mature (fully developed) sea is approximately 1.2 , implying that the wind and waves are moving at approximately the same speed. The wave age of younger seas fall below this value (i.e., developing or depth-limited waves where the wind speed is greater than the phase speed), while wave ages for older (decaying) seas fall above this value.

The lowest panel of Fig. 12 plots the bin-averaged results for three subsets of the data that were measured in young, mature, and old sea. The drag

Fig. 12. (top) Individual and (middle and bottom) binaveraged estimates of the neutral drag coefficient. The black lines labeled with C30 represents the COARE 3.0 parameterization from Fairall et al. (2003). (middle) The bin-averaged estimates are also compared with an average parameterization derived from Large and Pond (198I) and Smith (1980) denoted by L\&PS, and the HEXOS parameterization given by Smith et al. (1992) denoted by HEXI8. L\&PS and C30 were developed using ocean datasets, while HEXI8 was developed from data taken in coastal waters where the water depth was $18 \mathrm{~m}$. (bottom) Bin-averaged results for subsets of the data that were measured in young, mature, and old seas as characterized by the wave age parameter $c_{p} / U$. 
coefficients for a range of wave ages $\left(0.8<c_{p} / U<2\right)$ that includes mature seas are in good agreement with the COARE parameterization, which was developed using openocean observations. If the COARE parameterization is correct for mature seas at all wind speeds, then the bin-averaged results indicate that the drag coefficients of the younger seas are enhanced while those of the older seas are suppressed. Additionally, the drag coefficients of younger seas agree reasonable well with the formulation developed by Smith et al. (1992) during the Humidity Exchange over the Sea (HEXOS) experiment, which was conducted at a similar water depth.

The figure also shows, however, that the difference between the drag coefficients for wind speed bins that have more than one wave-age category is not significant. Therefore, these results, by themselves, are not sufficient to conclude that wave age is the cause for the discrepancy (i.e., COARE may simply overestimate the drag at low wind speeds for all wave ages). Nonetheless, we have reason to believe that swell impacts air-sea exchange at low winds based on previous field results (e.g., Smedman et al. 1999) and numerical simulations conducted for CBLAST. For example, our recent investigations of wind-swell interaction at low winds have been guided by LES studies by Sullivan et al. (2004), which clearly show that fast-moving swell in light winds can have a significant effect on the wind field up to heights of $O(100 \mathrm{~m})$, as shown in Fig. 13.

The LES results indicate that the dominant forces above the waves in this region are a wave-induced momentum flux divergence that accelerates the flow and a retarding pressure gradient, that is, opposite to the momentum balance in classical boundary layers. Under these conditions, the wave-driven winds produce a low-level jet and a rapid decay of the momentum flux with height (Sullivan et al. 2004). We have begun to investigate these processes using the ASIT data to examine the vertical structure of the turbulence in the surface layer, looking at how well the traditional predictions of the wind profiles compare with measurements over growing (young), fully developed (mature), and decaying (old) seas.

Other investigations of momentum exchange have focused on the ocean side of the air-sea interface. The subsurface array of turbulence sensors on ASIT

(Fig. 6) was used to directly measure heat and momentum fluxes. The oceanic momentum fluxes were estimated by direct covariance at $1.7-$ and $2.2-\mathrm{m}$ depths and checked against an independent method that relied on the airside measurements. The direct covariance estimates were made by integrating $u^{\prime} w^{\prime}$ cospectra (where $u^{\prime}$ is the horizontal and $w^{\prime}$ is the vertical velocity fluctuation, respectively) from zero up to an adaptive cutoff frequency below the wave band. This allowed estimation of the stresses carried in eddies approximately $1 \mathrm{~m}$ and larger. The independent estimates were made by assuming a slab-like mixed layer and interpolating between the measured wind stress at the surface and zero at the mixed layer base.

These estimates of stress match well at low wind speeds (Fig. 14), suggesting that all the stress at 1.7and 2.2-m depths is carried in eddies larger than $\sim 1 \mathrm{~m}$. Stress being carried by large eddies is consistent with the predictions of Kaimal et al. (1972) for turbulence generated by shear and convective instabilities. It is also consistent with observed sizes of coherent structures known as Langmuir circulations (Plueddemann et al. 1996). These investigations are aided by a an acoustic device known as the Bistatic Coherent Doppler Velocity Profiler (BDCVP) that provides 1-cm-resolution profiles of three component velocity vectors over a $1-m$ vertical span immediately below the water surface. These velocities allow the Reynolds stresses to be estimated through the near-surface water column in a surface-following coordinate system.

Mesoscale modulation of air-sea exchange. The sensible heat exchange driven by differences between the air and sea surface temperatures is a fundamental oceanic 


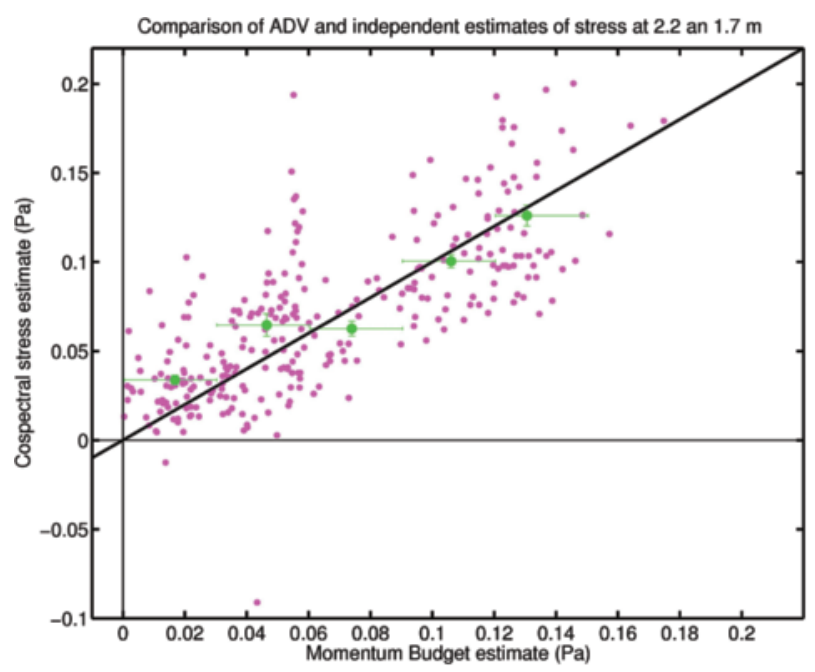

FIG. 14. Cospectral estimates of momentum flux measured at I.7- and 2.2-m depths versus an independent estimate from a momentum budget based on air-sea flux estimates. Small pink dots are individual burst measurements. Larger green dots are bin averages formed by binning in $\mathbf{0 . 0 2 - P a}$ increments along the horizontal axis. Vertical error bars denote two standard errors of the scattered observations about the bin average value. Horizontal bars show the extent of the bin from which each average was computed.

forcing of the atmosphere. The exchange impacts atmospheric forcing of the ocean through changes in stratification. SST during CBLAST-LOW had signifi- cant short-term temporal (e.g., diurnal) and smallscale (e.g., 5-10 km) spatial variability, which may have important impact on the atmosphere mesoscale forecast. Coordinated efforts during CBLAST-LOW were designed to observe and identify the processes that spatially modulate the vertical structure of the upper ocean, which, in turn, can modulate the air-sea exchanges that couple the boundary layers over a wide range of horizontal scales.

An illustrative example of coupled boundary layer dynamics, as well as of the coordinated observations made during CBLAST, is provided in Fig. 15. The oceanic temperature structure is highly resolved by the thermistor string towed from the Nobska. It shows the vertical structure beneath warm, cool, and warmer pools as seen from satellite imagery from north to south. The atmospheric structure is not as well resolved because of limitations of aircraft sampling. However, the measurements clearly indicate a cooling of the near surface over the cool water, and give some indication of warming over the warm water to the north. The surface fluxes are clearly responding to the spatial variability in the SST field. Dramatic change was seen in both latent and sensible heat fluxes (nearly $150 \mathrm{~W} \mathrm{~m}^{-2}$ total) as the vessel moved across the narrow oceanic frontal zone. However, there also appears to be a lag in the response over the warm water found downwind of the cool tongue. Snapshots like these over the course
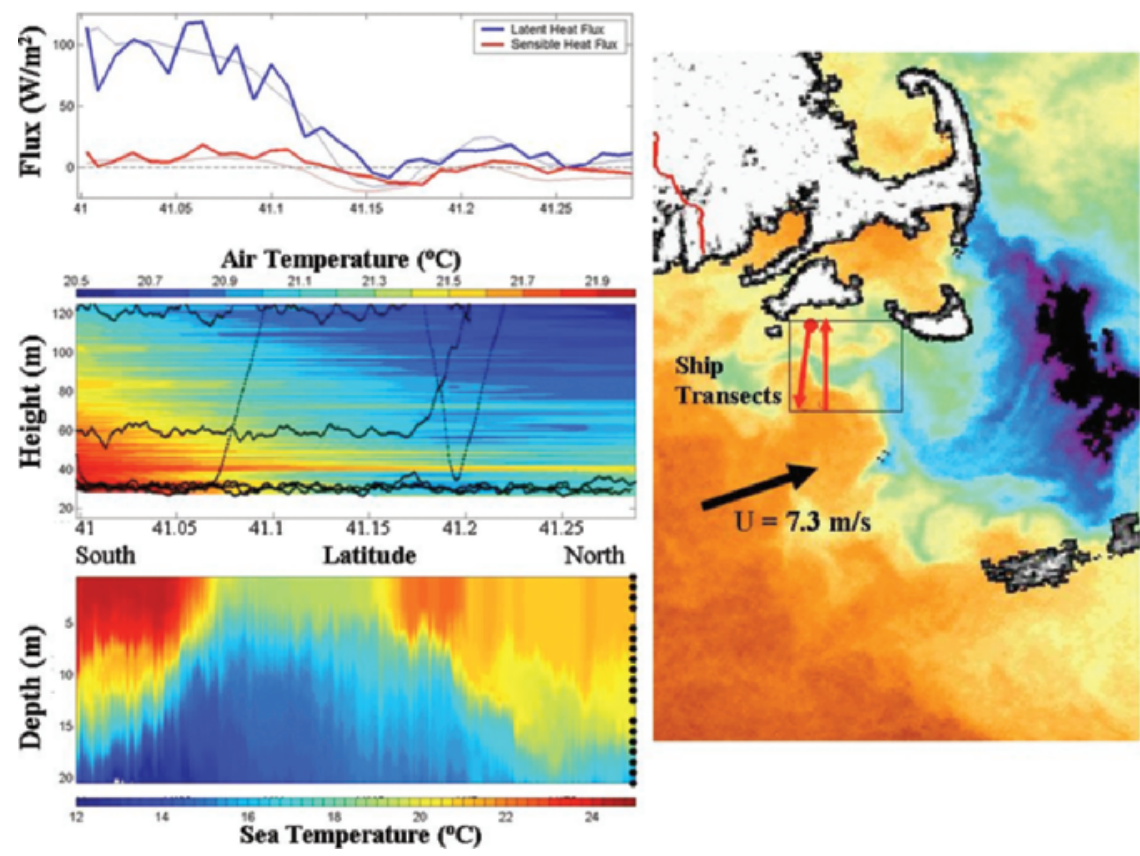

are from the second transect when the aircraft was overhead. The response of the atmospheric boundary layer to the SST field is evident, but the strong spatial variation of heat fluxes also affects the subsequent evolution of the SST field.
Fig. I5. (left, bottom) Ocean temperature structure, (middle) atmospheric temperature structure from the Pelican aircraft, and (top) sensible and latent surface heat fluxes. (bottom) The depths of the oceanic temperature sensors are indicated by the black dots. The location of the aircraft during low-, mid- and upper-level flux runs, as well as sawtooth soundings is shown by the black line in the middle plot. The transects were conducted by the F/V Nobska on the afternoon of 19 Aug 2003 as shown on the right. The fluxes were measured during the first transect when the Nobska was steaming into the wind as shown. The oceanic temperature measurements 
of the day show diurnal warming over the entire region. The rate at which subregions warm and the corresponding response of the mixed layer will depend on the magnitude of the surface fluxes "locked" over these subregions.

LES of SST variability was conducted to guide investigations of the effect of mesoscale SST variability on surface fluxes and the marine boundary layer structure (Skyllingstad et al. 2007). The basic scenario for the LES shown is to divide the simulation into regions of alternative warm/cold SST anomalies. Ambient air temperature upstream and well downstream of the anomaly region are set equal to the SST values in zones 1 and 4, respectively. This creates a neutrally stratified boundary layer upstream of the anomaly region. The boundary layer adjusts to neutral downstream from the anomaly region.

Simulations show that the spatial order, relative to the flow, of warm and cold anomalies has a direct impact on both the boundary layer structure and the surface fluxes over this downstream region. For example, when the warm anomaly (zone 2) is upstream from the cold anomaly (zone 3), the downstream boundary layer exhibits a complex structure because of enhanced convective forcing and mixed layer deepening upstream from the cold anomaly. An internal boundary layer forms over the cold anomaly in this case, generating two distinct layers over the downstream region (zone 4), as shown in Fig. 16.

These results suggest that, for SST differences of $2^{\circ}-4^{\circ} \mathrm{C}$ and mean wind speeds of $5-10 \mathrm{~m} \mathrm{~s}^{-1}$, SST variability on scales of 5-20 km should be directly simulated in mesoscale models. Parameterization of surface fluxes and boundary layer structure at these scales will be very difficult because of their dependence on subgrid-scale SST variability. However, simulations of similar flow over smaller-scale fronts $(<5 \mathrm{~km})$ indicate that small-scale SST variability might be represented in mesoscale models by relating the effective heat flux to the strength of SST variance.

Stable boundary layers and fog. As with terrestrial boundary layers, our understanding and ability to simulate processes in stratified (stable) marine ABLs lags our understanding of convective ABL processes. Over the past several decades, marine investigations have concentrated on neutral to slightly convective MABLs and our parameterizations have been tuned to these conditions (e.g., Edson et al. 2004). In contrast, oceanographers have focused on neutral to stratified boundary layers and the inherent complexity that arises due to patchy and intermittent turbulence.

The ABL over the CBLAST region was typically stable during the first half of the summer resulting from the combination of advection and a slowly warming coastal ocean (Crofoot 2004). This is a common occurrence along the East Coast during the late spring and early summer. Stable marine ABL is also a common occurrence on the West Coast, particularly when northerly winds drive coastal upwelling. As residents of both coasts can attest, these stable MABLs are often characterized by fog and cool summertime weather.

The uncertainty in the determination of the momentum and scalar fluxes remains one of the main obstacles to accurate numerical forecasts in stable MABLs. For example, our initial investigations have shown significant differences between direct covariance and bulk fluxes in stable conditions, particularly 
when the moisture flux is directed downward (Fig. 17). These periods of downward moisture flux are often associated with foggy conditions, as shown in Fig. 18. The CBLAST data indicate that the Dalton numbers remain lower than the COARE algorithm parameterization even after removal of downward fluxes and foggy periods (Fig. 19). Therefore, improvement of heat

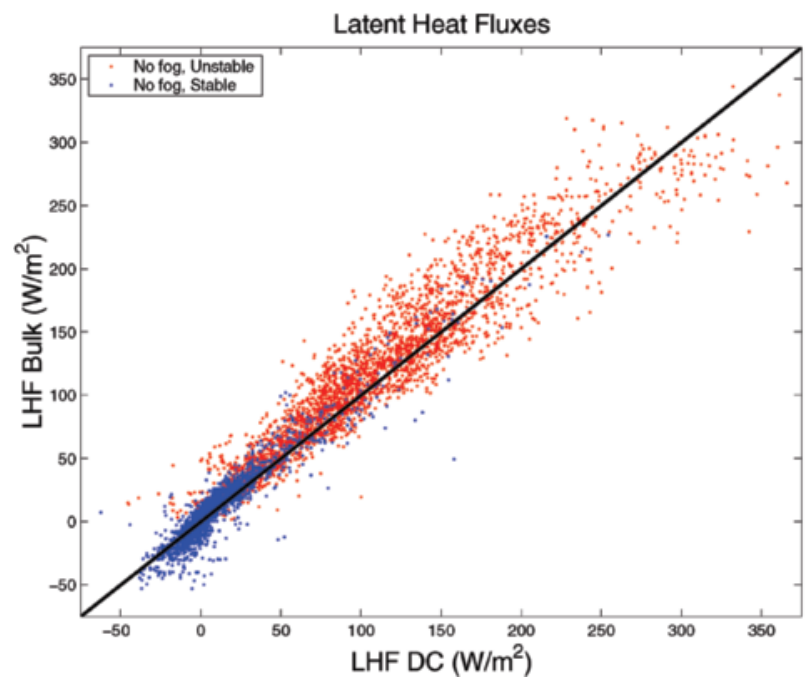

FIG. 17. Comparison of bulk aerodynamic versus direct covariance latent heat fluxes measured from ASIT. The red dots indicate unstable conditions (i.e., positive buoyancy flux) while the blue dots indicate stable conditions (i.e., negative buoyancy flux).

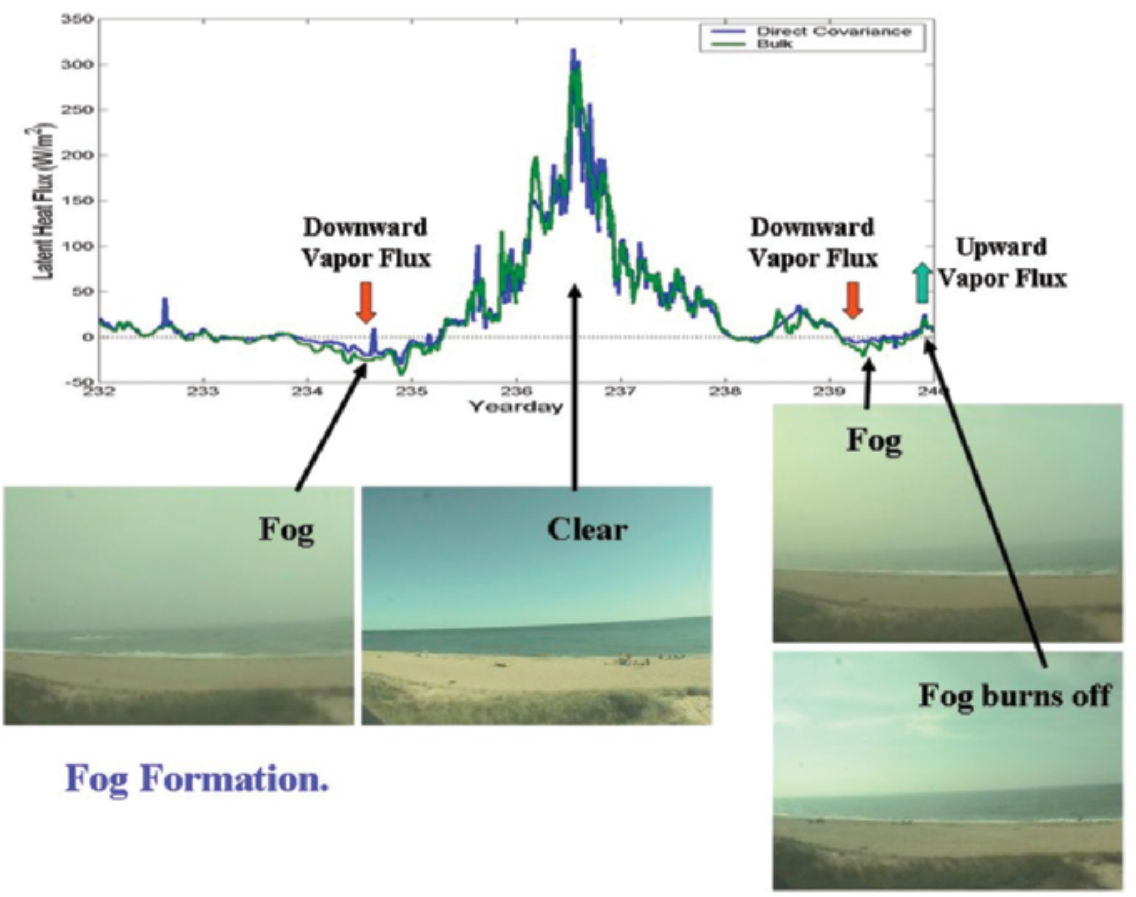

FIG. 18. Time series of the latent heat fluxes and visual evidence for the presence of fog during periods of downward moisture flux. flux parameterizations in stable conditions is a main objective of ongoing investigations.

COAMPS analysis has shown that improved parameterizations are only part of the improvements required for accurate forecasts of fog. For example, COAMPS runs have shown that its ability to predict fog is extremely sensitive to the SST used in the model. These sensitivity tests indicate that a $4^{\circ} \mathrm{C}$ increase in SST forces the model prediction to go from heavy fog to no fog, as shown in Fig. 20. The strong dependence of fog formation on SST should come as no surprise. However, SST variability of several degrees is the rule rather than the exception in coastal regions where, as shown by ROMS, upwelling and lateral advection often dominate the dynamics.

Therefore, the real point of the sensitivity test was to illustrate the importance of accurate SST estimates at higher spatial and temporal resolution than is normally available, particularly in coastal regions. One main reason for the lack of SST estimates is due to weather systems that often obscure the surface with clouds and fog, which is impenetrable to IR remote sensing. New technologies are able to peer through clouds and fog, but these suffer from low resolutions and biases. Therefore, a reasonable solution to this problem is to develop a truly coupled atmosphereocean forecast system that provides the necessary spatial and temporal resolution, complemented with improved estimates of SST from remote and in situ observing systems. CBLAST investigations continue with this goal in mind.

SUMMARY. An unprecedented dataset was collected on both sides of the ocean-atmosphere interface during the CBLAST-LOW experiments. This included the first direct measurements of heat and momentum exchange on both sides of the air-sea interface. These measurements are being used to investigate processes that govern the exchange of momentum, heat, and mass across the coupled boundary layers. These process studies have involved close collaboration with numerical modelers and many of these 

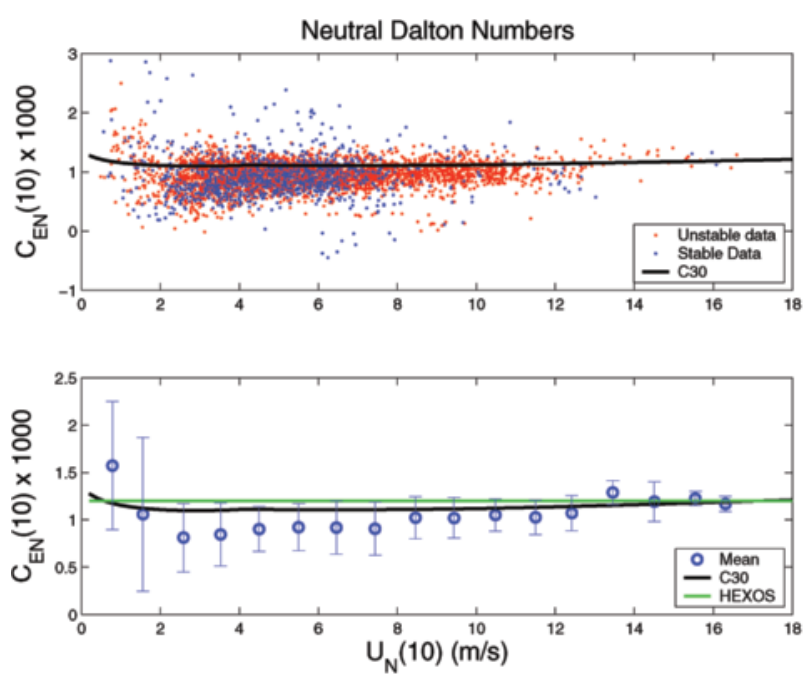

FIG. 19. Individual and bin-averaged estimates of the neutral Dalton number. The black lines labeled with C30 represents the COARE 3.0 parameterization from Fairall et al. (2003), while the green line represents the HEXOS parameterization from DeCosmo et al. (1996).

investigations are guided by the numerical simulations summarized in Table 2. Our initial investigations indicate that ocean waves and wave-related processes have a significant impact on air-sea exchange and coupled boundary layer processes, even under light wind conditions. These studies have also shown that mesoscale and finer-scale variability in the SST field strongly modulates the vertical structure of the coupled boundary layers. Continued investigations are expected to improve the predictive capabilities of a coupled air-sea models.

ACKNOWLEDGMENTS. This work was supported by the Office of Naval Research. The manuscript was put together by the CBLAST Program Office using support from ONR Grants N00014-00-1-0409 and N00014-05-10139. Many of deployment activities for CBLAST-LOW were supported by the MVCO management team. In particular, the principal investigators acknowledge the support provided by Janet Fredericks, Stephen Faluotico, Margaret McElroy, and Jay Sisson.

This research is dedicated and in tribute to the late Dr. Timothy Crawford (1948-2002), director of the Field Research Division (FRD) of the National
Oceanic and Atmospheric Administration's (NOAA's) Air Resources Laboratory (ARL). Tim always stated "It's not about the flying. It's about the science." The scientific community suffered a tragic loss with his passing on 3 August 2002. He was 53 years old.

\section{REFERENCES}

Austin, T., and Coauthors, 2002: A network-based telemetry architecture developed for the Martha's Vineyard coastal observatory. IEEE J. Oceanic Eng., 27, 228-234.

Black, P. G., and Coauthors, 2007: Air-sea exchange in hurricanes: Synthesis of observations from the coupled boundary layer air-sea transfer experiment. Bull. Amer. Meteor. Soc., 88, 357-374.

Businger, J. A., 1988: A note on the Businger-Dyer profiles. Bound.-Layer Meteor., 42, 145-151.

Chen, S. S., J. F. Price, W. Zhao, M. A. Donelan, and E. J. Walsh, 2007: The CBLAST-Hurricane Program and the next-generation fully coupled atmosphere-waveocean models for hurricane research and prediction. Bull. Amer. Meteor. Soc., 88, 311-317.

Crofoot, R. F., 2004: Investigations of scalar transfer coeficients in fog during the Coupled Boundary Layers and Air-Sea Transfer experiment: A case study. M.S. thesis, WHOI/MIT Joint Program, Dept. of Applied Ocean Physics and Engineering, 72 pp.

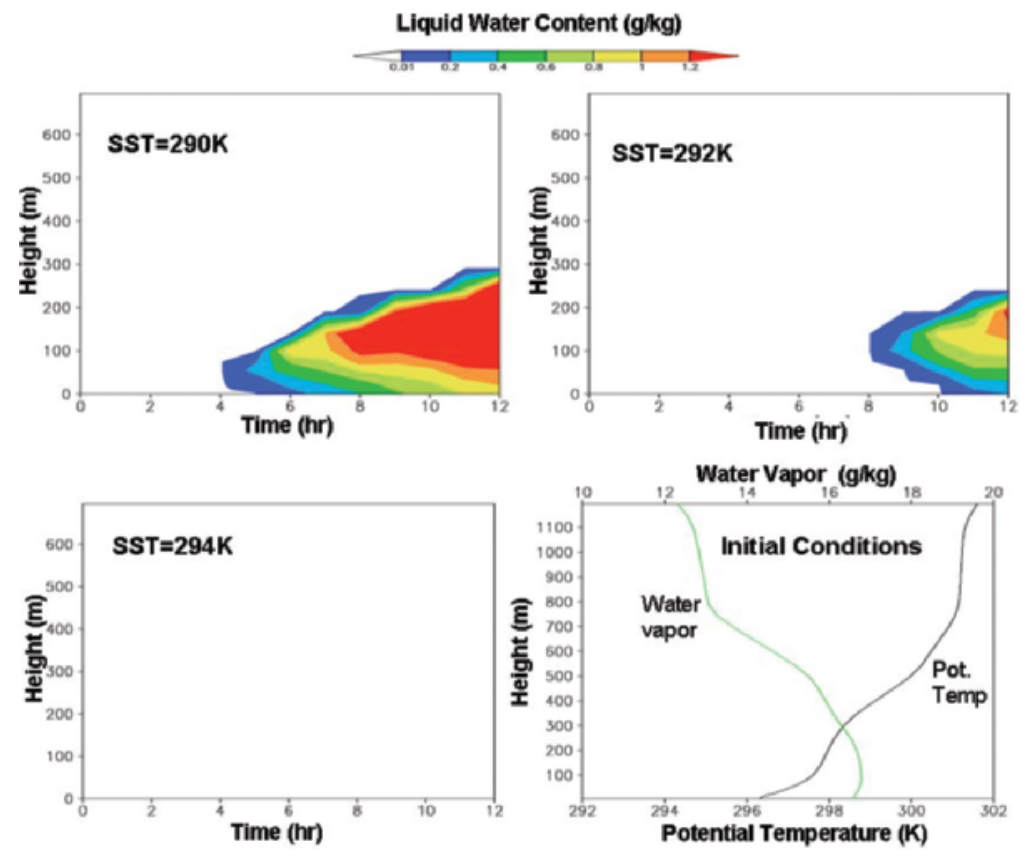

FIG. 20. The sensitivity of fog formation to SST as indicated by model predictions of liquid water content for the three SSTs shown. The lower right panel shows the initial conditions in the ABL for each of the three runs. 
DeCosmo, J., K. B. Katsaros, S. D. Smith, R. J. Anderson, W. A. Oost, K. Bumke, and H. Chadwick, 1996: Airsea exchange of water vapor and sensible heat: The humidity exchange of the sea experiment (HEXOS) results. J. Geophys. Res., 101 (C5), 12 001-12 016.

Edson, J. B., C. J. Zappa, J. A. Ware, W. R. McGillis, and J. E. Hare, 2004: Scalar flux profile relationships over the open ocean. J. Geophys. Res., 109, C08S09, doi:10.1029/2003JC001960.

Fairall, C. W., E. F. Bradley, J. E. Hare, A. A. Grachev, and J. B. Edson, 2003: Bulk parameterization of airsea fluxes: Updates and verification for the COARE algorithm. J. Climate, 16, 571-591.

Hare, J. E., T. Hara, J. B. Edson, and J. M. Wilczak, 1997: A similarity analysis of the structure of air flow over surface waves. J. Phys. Oceanogr., 27, 1018-1037.

He, R., and J. L. Wilkin, 2006: Barotropic tides on the southeast New England shelf: A view from a hybrid data assimilation modeling approach. J. Geophys. Res, 111, C08002, doi:10.1029/2005JC003254.

Hodur, R. M., 1997: The Naval Research Laboratory's Coupled Ocean/Atmosphere Mesoscale Prediction System (COAMPS). Mon. Wea. Rev., 125, 1414-1430.

Hristov, T. S., S. D. Miller, and C. A. Friehe, 2003: Dynamical coupling of wind and ocean waves through wave-induced air flow. Nature, 442, 55-58.

Kaimal, J. C., J. C. Wyngaard, Y. Izumi, and O. R. Coté, 1972: Spectral characteristics of surface-layer turbulence. Quart. J. Roy. Meteor. Soc., 98, 563-589.

Kraus, E. B., and J. S. Turner, 1967: A one-dimensional model of the seasonal thermocline. II. The general theory and its consequences. Tellus, 19, 98-105.

Large, W. G., and S. Pond, 1981: Open ocean momentum flux measurements in moderate to strong winds. $J$. Phys. Oceanogr., 11, 324-336.

— , J. C. McWilliams, and S. C. Doney, 1994: Ocean vertical mixing: A review and a model with a nonlocal k-profile boundary layer parameterization. Rev. Geophys., 32, 363-403.

Louis, J. F., 1979: A parametric model of vertical eddy fluxes in the atmosphere. Bound.-Layer. Meteor., 17, 187-202.

Mellor, G. L., and Yamada, T., 1982: Development of a closure model of geophysical flows. Rev. Geophys. Space Phys., 20, 851-875.

Plueddemann, A. J., J. A. Smith, D. M. Farmer, R. A. Weller, W. R. Crawford, R. Pinkel, S. Vagle, and A. Gnanadesikan, 1996: Structure and variability of Langmuir circulation during the Surface Wave Processes Program. J. Geophys. Res., 101 (C2), 3525-3543.
Price, J., R. Weller, and R. Pinkel, 1986: Diurnal cycling: Observations and models of upper ocean response to diurnal heating, cooling and wind mixing. $J$. Geophys. Res., 91, 8411-8427.

Pritchard, M., and R. Weller, 2005: Observations of internal bores and waves of elevation on the New England inner continental shelf during summer 2001. J. Geophys. Res., 110, C03020, doi:10.1029/ 2004JC002377.

Skyllingstad, E. D., D. Vickers, L. Mahrt, and R. Samuelson, 2007: Effects of mesoscale sea-surface fronts on the marine boundary layer. Bound.-Layer Meteor., in press.

Smedman, A., U. Högström, H. Bergström, A. Rutgersson, K. K. Kahma, and H. Petersson, 1999: A case study of air-sea interaction during swell conditions. J. Geophys. Res., 104, 25 833-25 851.

Smith, S. D., 1980: Wind stress and heat flux over the ocean in gale force winds. J. Phys. Oceanogr., 10, 709-726.

— drag coefficients: The HEXOS results. Bound.-Layer Meteor., 60, 109-142.

Sullivan, P. P., J. B. Edson, J. C. McWilliams, and C.-H. Moeng, 2004: Large-eddy simulations and observations of wave-driven boundary layers. Preprints, 16th Symp. on Boundary Layers and Turbulence, Portland, ME, Amer. Meteor. Soc., CD-ROM, 8.12.

Vickers, D., and L. Mahrt, 1999: Observations of nondimensional wind shear in the coastal zone. Quart. J. Roy. Meteor. Soc., 125, 2685-2702.

- _ - J. Sun, and T. Crawford, 2001: The structure of offshore flow. Mon. Wea. Rev., 129, 1251-1258.

$\longrightarrow$, and — 2006: Evaluation of air-sea flux bulk formula and sea-surface temperature variability based on aircraft and tower observations. J. Geophys. Res., 111, doi:10.1029/2005JC003323.

Wang, S., Q. Wang, and J. Doyle, 2002: Some improvement of Louis surface flux parameterization. 15th Symp. on Boundary Layers and Turbulence, Wageningen, the Netherlands, Amer. Meteor. Soc., 547-550.

Wilkin, J., 2006: Modeling the summertime heat budget and circulation of southeast New England shelf waters. J. Phys. Oceanogr., 36, 1997-2011.

— sis models for coastal observatories. Ocean Weather Forecasting: An Integrated View of Oceanography, E. Chassignet and J. Verron, Eds., Springer, 549-572.

Zappa, C. J., and A. T. Jessup, 2005: High resolution airborne infrared measurements of ocean skin temperature. Geosci. Remote Sens. Lett., 2, 146-150. 